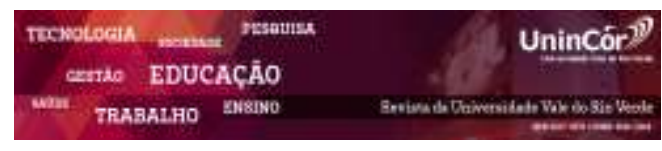

Revista da Universidade Vale do Rio Verde ISSN: 1517-0276 / EISSN: 2236-5362 Vol. 16 | n. 1 | Ano 2018

Geraldo Carlos Silvestre Pontifícia Universidade Católica de São Paulo PUCSP gcsgebolol@gmail.com

Neusa Maria Bastos Fernandes dos Santos Pontifícia Universidade Católica de São Paulo -

PUCSP

admneusa@pucsp.br

Benedito Geovani Martins de Paiva Pontifícia Universidade Católica de São Paulo PUCSP

benedito.geovani@yahoo.com

\section{NOVAS FORMAS DE PARTICIPAÇÃO \\ NA GESTÃO PÚBLICA: UM SISTEMA \\ ALTERNATIVO PARA GARANTIR A \\ PARTICIPAÇÃO EFETIVA DA COMUNIDADE LOCAL}

\section{RESUMO}

A partir da Constituição Federal de 1988, com o advento da descentralização do poder, dando aos municípios autonomia para planejamento e execução das políticas urbanas de desenvolvimento, a sociedade passou a ter um papel de poder local que pode ser fundamental para a melhoria da qualidade de vida, desde que tenha uma participação efetiva e continua na gestão pública. Este estudo tem como objetivo discutir as principais formas de participação da sociedade na gestão pública e propor um sistema alternativo de participação direta da comunidade local. A partir do levantamento bibliográfico foram identificados os estudos sobre experiências de participação na gestão pública de municípios brasileiros. As discussões sobre as experiências propiciaram destacar os principais aspectos e limitações das formas de participação, indicando como mais adequado que o cidadão participe desde o início do processo, ou seja, a partir de planejamento participativo, com a proposição de um sistema de participação direta da comunidade local.

Palavras-chave: Gestão Pública Participativa. Planejamento Participativo. Comunidade Local.

\section{NEW WAYS TO PARTICIPATE IN PUBLIC MANAGEMENT: AN ALTERNATIVE SYSTEM TO ENSURE EFFECTIVE LOCAL COMMUNITY INVOLVEMENT}


for the citizen to participate from the beginning of the process, that is, from the participatory planning, with the proposal of a system of direct participation of the local community.

Keywords: Participative Public Management. Participatory Planning. Local Community.

Recebido em: 10/11/2017 - Aprovado em: 05/04/2018 - Disponibilizado em: 15/07/2018

\section{INTRODUÇÂO}

A participação da população nas decisões da gestão pública é um assunto que à primeira vista, parece sugerir um formato ideal de gestão. Entretanto, não é difícil imaginar que uma cidade como São Paulo, por exemplo, a participação da população pode ampliar demasiadamente as discussões e o processo de decisão torna-se moroso, enquanto que a gestão centralizada reduz demasiadamente os debates e, por isso as decisões podem não representar os desejos da comunidade local, sendo assim, ineficientes. Desse dilema, o que temos como adequado é que a participação da população é saudável e as decisões por ela pautadas são mais eficientes, pois provavelmente apresentarão soluções efetivas e factíveis para os problemas da comunidade. $\mathrm{O}$ grande desafio é estruturar um formato de participação que desperte o interesse do cidadão e que verdadeiramente funcione como elemento de contribuição para o planejamento e execução de políticas públicas que representem as demandas da comunidade local. Nesse sentido, teríamos dois aspectos a serem tratados. De um lado o poder público que deve promover e provocar a participação e adesão da sociedade e de outro lado, que a sociedade tenha maior interesse em participar e resolver os seus próprios problemas. Assim, esse estudo propõe a criação de um sistema de informações capaz de capturar, organizar e analisar os reais desejos e necessidades da comunidade local, por meio da participação direta, sem a participação de representantes intermediários.

\section{REFERENCIAL TEÓRICO}

As formas tradicionais de participação do cidadão nas políticas públicas ocorrem de duas formas: a primeira pelo eixo político partidário, mediante eleição de representantes no poder executivo e legislativo; e o segundo eixo, sindical trabalhista, mediante negociações empresariais e greves (DOWBOR, 2008). O autor acrescenta a importância de um terceiro eixo, denominado "espaço local" que tem como instrumento a organização comunitária, fazendo com que as pessoas exerçam o direito e o poder de transformar os locais onde vivem para melhor qualidade de vida e não simplesmente mudar de bairro ou cidade e deixar os problemas para trás. Dowbor enfatiza que "[...] este 'terceiro eixo' está abrindo um espaço político profundamente renovador na nossa concepção de democracia" (DOWBOR, 2008, p. 7). 
Uma questão é se a democracia local tem o poder para reforçar a coesão e justiça social? Ou seja, se os impactos de fato contribuem para redução das desigualdades, pois a participação da comunidade representa relações de poder que irão decidir sobre destinação e utilização de recursos. Outra questão é se a democracia participativa aumenta a eficácia da administração pública? O que constitui um dos seus principais objetivos. O reforço da eficácia é defendido por três linhas de argumentação: i) a proximidade fornece melhor capacidade de entendimento e avaliação dos problemas e consequentemente acerto nas decisões; ii) o processo de participação envolve um grande número de atores o que faz aumentar a possibilidade de êxito da gestão; e iii) ocorre um processo de fiscalização automática pelos envolvidos e principais interessados nas soluções dos problemas (GUERRA, 2010).

Guerra (2010) assevera que não há unanimidade quanto aos resultados práticos das experiências de participação local. Críticas são feitas pelo excesso de burocratização, diluição da decisão deixando-as sem identidade, representação em maioria por organizações institucionalizadas e contradições entre gestão hierarquizada e horizontal.

Existe uma tendência mundial de promover estratégias para viabilizar o conceito de "governo aberto" que está fundamentado nos princípios de transparência, prestação de contas, participação e colaboração. Esse movimento é uma resposta às limitações e ineficiências dos modelos tradicionais de governança (RAMÍREZALUJAS, 2012).
Como efeito da globalização a maioria das cidades da América Latina, principalmente aquelas menos competitivas e menos organizadas, tiveram uma piora dos seus resultados sociais. Governos e cidadãos, efetivamente, ainda não perceberam a necessidade de uma nova cultura de participação na gestão pública (GARCIA, 2015).

Dowbor (2013), em seu artigo "Por uma São Paulo inteligente: Espaços de governança" faz uma proposta para a melhoria da qualidade de vida a partir de uma gestão mais eficiente, orientada por cinco pontos de modernização da governança: i) Informação compartilhada: elemento que dá fluidez e consistência ao processo decisório; ii) planejamento participativo, envolve articulações integradas que garante equilíbrio aos interesses públicos, privados e das sociedade em geral, fundamentadas em estudos técnicos com visão conjunta e de resultados de longo prazo; iii) acesso à banda larga: conectividade, o acesso a conectividade à internet é tão essencial quanto o acesso a água e eletricidade, por exemplo, pois além de contribuir para os efeitos de participação, reduz a desigualdade de oportunidades; iv) comunidade organizada: democracia participativa, envolve a participação dos moradores locais nas escolhas e nas opções daquilo que deve e será feito para melhorar a qualidade de vida local; e v) conselhos de desenvolvimento, irá pensar um plano de desenvolvimento local de longo prazo, constituído como um espaço de governança com representação participativa de todos os segmentos, sobretudo, agentes públicos, 
empresários, organizações da sociedade civil, sindicatos e universidades.

O movimento de participação aumenta o poder dos membros da sociedade enquanto produtores, incluindo-os na esfera pública da partilha de informação e de poderes com os eleitos, gestores e técnicos. Essa partilha de poder não se faz sem conflitos, quer entre as visões do mundo, quer na partilha das competências técnicas, quer ainda nas negociações de interesses entre os vários atores. (GUERRA, 2010, p. 129130)

Diante de tudo que foi exposto, não há dúvida quando à necessidade de adotar novas formas de participação para garantir uma melhor qualidade de vida. Isso implica diretamente, na modernização dos modelos tradicionais de governança.

\section{SURGIMENTO, IMPLEMENTAÇÃO E CONSEQUÊNCIAS DAS NOVAS FORMAS DE PARTICIPAÇÃO}

Não é possível discutir as formas de participação sem entender a estrutura política brasileira. As definições e as escolhas das formas de participação são dependentes da estrutura federativa e das atribuições e poderes dos entes federativos.

Os avanços da democracia e da participação pelo olhar da descentralização e do poder local são melhores explicados por duas perspectivas teóricas. A primeira, com relação aos receios do poder brasileiro quanto ao sistema socialista e a segunda, a experiência anglo-saxã, na ótica de Tocqueville, que enfatiza a comunidade local. No brasil, o poder local foi por muito tempo apropriado e dominado pelos "coronéis". Por essa razão, faz sentido que as constituições federais brasileiras voltadas para o interesse popular, como as de 1930 e 1946, tivessem como motivação e justificativa para centralização do poder, o combate às ações dos “coronéis" (FONSECA, 2007)

Os primeiros anúncios formais de descentralização que fazem surgir novas formas de participação na administração pública têm como marco regulatório a Constituição Federal de 1988, como reflexo das pressões populares em decorrência do desencantamento com a forma tradicional de participação através da democracia representativa. Assim, a sociedade percebeu a necessidade da participação direta no processo decisório e, a partir da Constituição de 1988, as legislações infraconstitucionais trataram de assegurar várias formas de participação, que são: audiências e consultas públicas, cooperação de entidades representativas da sociedade civil em diversas áreas, participação e cooperação dos usuários na prestação de serviços públicos, orçamento participativo, ouvidorias gerais, gestão paritária de serviços e políticas públicas (FERRAZ, 2008). Destaca-se também que a constituição de 1988 veio para refletir as conquistas democráticas e em resposta ao fim do regime militar, no seu parágrafo único do artigo $1^{\circ}$ imprimiu a legitimidade da participação popular determinando que: "Todo o poder emana do povo, que o exerce por meio de representantes eleitos ou diretamente, nos termos desta Constituição". (grifo do autor) 
Tocqueville (2015), analisou e concluiu que a experiência francesa, que a até o ano de 1787 tinha duas formas de administração pública, centralizada e descentralizada, de unificação da administração para a forma descentralizada, mediante criação de assembleias provinciais e corpo provincial em substituição ao intendente, combinada com mudanças radicais na legislação, foi suficiente para que as assembleias provinciais criadas em 1787 "[...]imediatamente depois de nascerem elas entraram em guerra velada e frequentemente aberta com os intendentes[...]". Diante dessas alterações e outros fatores, Tocqueville afirmou que a situação que era confusa se tornou um "Terror", e faz a seguinte reflexão:

É bastante estranho que, em uma sociedade tão esclarecida e em que a administração pública desempenhava já há muito tempo um papel tão grande, nunca se tenha pensado em reunir os dois sistemas e em distinguir, sem desagrega-los, o poder que deve executar e o poder que deve fiscalizar e prescrever (TOCQUEVILLE, 2015, p. 172-173).

A organização da participação como fruto da descentralização deve ocorrer paulatina e progressivamente, à justa medida da correspondente capacidade de execução, pois será necessária mudança de cultura administrativa dos agentes públicos e da comunidade, consensos da sociedade civil em um espaço determinado, transparência e clareza nas propostas e interesses e personalização do modelo de gestão de participação comunitária, considerando as características, recursos, limitações de cada município (DOWBOR, 2008).

A implementação das formas de participação, determinadas na Constituição, que representa, em relação aos períodos anteriores, uma maior autonomia concedida aos municípios e à sociedade em geral, deve transcorrer em um processo de migração cultural, de educação dos cidadãos, e de consciência dos administradores públicos do seu objetivo principal de melhorar a qualidade de vida da comunidade local. Para isso, é imprescindível dar voz ao cidadão no processo de definição e implementação das políticas públicas.

\section{PARTICIPAÇÃO COMO EXERCÍCIO DA CIDADANIA}

O processo de descentralização significa também a ampliação do poder democrático que exige, para seu pleno exercício, a participação efetiva e direta da população e da sociedade civil organizada. A vontade do povo expressada na Constituição Federal perde seu significado quando a sociedade se afasta do direito e do dever de participação na gestão pública.

A democracia é um fenômeno hegemônico no lado ocidental do planeta, não simplesmente como elemento de escolha de governantes, mas no seu conjunto de atributos intrínsecos, sendo a liberdade e a igualdade os mais evidentes. Nesse sentido, é inquestionável a legitimidade do povo em definir diretrizes a serem seguida pelos governos, entretanto, não há consenso quanto aos mecanismos mais adequados e eficazes para o exercício desse poder democrático (DIAS, 2004). 
De acordo com artigo 182 da Constituição, a política de desenvolvimento urbano é atribuição do poder público municipal e tem como objetivo ordenar o pleno desenvolvimento das funções sociais da cidade e garantir o bem-estar de seus habitantes. O referido dispositivo constitucional foi regulamentado pela Lei 10.257/2001, cujo inciso II do artigo $2^{\circ}$ dispõe que para atendimento ao artigo 182 da CF/88, estabelece como diretriz a gestão democrática por meio da participação da população e de associações representativas dos vários seguimentos da comunidade na formulação, execução e acompanhamento de planos, programas e projetos de desenvolvimento urbano.

A partir dessa legislação cabe a cada município definir as suas melhores formas de participação. O grande problema não de é cunho legal, pois a lei está aí vigente. O maior desafio é promover o interesse da população para uma participação efetiva e continua. Os grandes municípios já possuem estruturas para participação, entretanto, não basta oferecer uma estrutura, é necessário de fato querer que a população participe.

Um estudo realizado sobre a forma de participação na Cidade de Belo Horizonte, por meio do Conselho Municipal de Política Urbana (COMPUR), órgão instituído para atuar no planejamento das políticas públicas urbanas com foco especifico na solução de demandas da vida urbana do Município de Belo Horizonte, revelou

\footnotetext{
${ }^{1}$ Órgão composto por 16 membros efetivos, sendo 8 representantes do poder Executivo, 2 do poder Legislativo e 6 da sociedade civil (distribuídos em três
}

as características do interesse de participação da sociedade civil. As associações e organizações da sociedade civil, demonstram grande interesse em participar e disputam eleições para manterem seus representantes no COMPUR e escolhem e indicam seus delegados para participarem das conferências organizadas pelo COMPUR. O interesse de participação do cidadão comum, geralmente é motivado por ocasião de problemas que afetam a comunidade local, bairros e regiões. O COMPUR existe desde 1996, entretanto, pesquisas sobre o conhecimento popular do órgão, indicaram que $74,1 \%$ dos entrevistados declararam conhecer o órgão, mas a maioria não sabe o que o órgão faz e apenas $6,5 \%$ sabe que o órgão organiza as Conferências de Políticas Urbanas. Pesquisa com delegados da II Conferência Municipal de Política Urbana, revelou que o grande problema da participação é o baixo interesse da população (COSTA, 2013).

Na cidade de São Paulo, Rizzi (2011) efetuou estudo sobre a participação da comunidade do Distrito de Perus, que a partir de 2001, entrou em discussão em relação ao destino do Aterro Bandeirantes, que iniciou atividade em 1978 e foi desativado em 2006 após receber aproximadamente 30 milhões de toneladas de lixo. De acordo com Rizzi (2011), as recomendações de especialistas e a vontade da comunidade era a implantação de um parque sobre o Aterro. Porém, o poder público municipal decidiu pela exploração econômica do Aterro, mediante geração de energia elétrica através da combustão de gás metano. A viabilização econômica foi concebida pela

setores de representação - 2 técnicos, 2 populares, 2 empresariais). 
criação do Projeto MDL - Mecanismo de Desenvolvimento Limpo. Na afirmação do autor, o referido projeto se trata de um "processo de alijamento da participação local na condução do projeto[...]e formado o monopólio dos grandes atores hegemônicos da captação, geração, distribuição e consumo de energia elétrica[...] (RIZZI, 2011, p.1).

O estudo de Rizzi nos demonstra como organizações $^{2}$ foram capazes de se articularem com o poder público, o qual, ignorou completamente as recomendações de especialistas e sobretudo a vontade da população local. O mais intrigante ainda é que o projeto MDL que é vinculado ao Protocolo de Kyoto, exige a participação da comunidade local.

Os dois estudos trazidos ao debate mostram duas configurações diferentes, em um caso existe uma estrutura de participação definida, entretanto, não existe $\mathrm{o}$ interesse de participação popular. No outro caso, a participação da comunidade local foi afastada por interesses puramente econômicos, com o consentimento do poder público.

Isso conduz a conclusão de que a participação da sociedade tem que encontrar um espaço de intersecção com o poder público. Esse espaço deve ser ocupado pelo desejo e interesse indelegável de participar do cidadão e pelo dever do poder público em prover todos os meios para a participação popular e, sobretudo respeitar as suas decisões.

2 O Consórcio Bandeirantes que deu origem ao Projeto MDL, era formado pela Prefeitura de São Paulo, Biogás (empresa geradora de energia), o Banco Mundial e o BIRD.

\section{LIMITAÇÕES DO ORÇAMENTO PARTICIPATIVO}

A Cidade de Porto Alegre foi a criadora e a primeira a implementar o Orçamento Participativo (OP) em 1989. Após a experiência de Porto Alegre, o OP foi adotado por mais de 300 prefeituras brasileiras (entre 1989 e 2004), e também em cidades de aproximadamente trinta países (WAMPLER, 2008).

O OP tem como princípios fundamentais que nortearam a sua concepção, a democracia, a equidade, a solidariedade e eficiência, elementos que teria melhorado a qualidade de vida, principalmente, da população de baixa renda, sendo considerado por alguns um instrumento de democracia redistributivo (MARQUETTI, 2003)

$\mathrm{Na}$ experiência de implementação do $\mathrm{OP}$ na cidade de Campinas, o grande desafio foi o de desmontar armadilhas administrativas, reestruturar o aparato do poder público e inverter a ordem de prioridades de investimentos de um olhar público para um olhar das necessidades da comunidade. Nesse processo, os movimentos sociais tiveram papel fundamental, pois a organização da sociedade é condição básica (BRAGA, 2005).

O Orçamento Participativo, talvez seja a experiência mais positiva em termos de modelo de forma de participação, mas também é um formato complexo. A sua capacidade de captação e solução de problemas pode ser ampliada com a efetiva participação da sociedade.

$\mathrm{O}$ OP não pode ser visto e entendido apenas como um instrumento de destinação dos recursos públicos. Esse aspecto atrai as entidades da organização civil, mas não a população 
comum. A grande alegação é que a participação direta da população na alocação de recursos se justifica porque e ela quem melhor conhece suas necessidades e prioridades. Isso é verdadeiro, mas uma participação plena e adequada deve ter início no planejamento, momento em que a comunidade fará suas escolhas de acordo com suas necessidades, prioridades e peculiaridades, sendo mandatório participar e discutir a formação de suas receitas. Por exemplo: a comunidade local pode entender que a redução de tributo será adequada e oportuna para incentivar o setor econômico e consequentemente aumentar o nível de geração de emprego local, propiciando que seus moradores trabalhem próximos de suas casas, reduzindo o tempo gasto com deslocamento e aumento do tempo de convivência com suas famílias, ou seja, melhorando a qualidade de vida. Nesse formato, um aparente prejuízo pela redução de receita pode implicar uma relação custo/benefício interessante para a comunidade local.

Assim, as decisões de gastos e investimentos orçamentários devem ser uma consequência das políticas públicas preestabelecidas mediante o amplo debate participativo com a comunidade local, ou seja, planejamento participativo. Desse modo a participação da sociedade não estará limitada à alocação dos recursos, fato que provoca uma corrida das organizações da sociedade civil para obter a maior fatia dos recursos disponíveis para atendimento de suas causas especificas que podem não representar o interesse coletivo.

\section{PROPOSTA DE SISTEMA ALTERNATIVO DE PARTICIPAÇÃO}

A participação na gestão pública deve buscar formas criativas e alternativas para alcançar seu principal objetivo que é envolver a comunidade local no planejamento, implementação, execução e monitoramento das políticas públicas. Esse envolvimento da sociedade, conforme Dowbor (2008) requer a uma transformação da cultura administrativa e um processo gradual e sistemático.

A participação democrática atravessou algumas fases no seu processo de evolução. Antes de entrar em processo de evolução, experimentou o rompimento do regime militar, sendo essa primeira fase de revolução e a Constituição de 1988 retrata exatamente isso. Uma segunda fase é o período de implementação e adaptação às novas formas de participação, nessa fase teríamos as eleições diretas para a participação representativa e o surgimento do orçamento participativo, como forma de participação direta. A terceira fase compreende a adesão ao orçamento participativo por vários munícipios e o aprimorando pelo aprendizado das experiências de participação. A quarta fase, a atual, busca formas alternativas de participação considerando os avanços tecnológicos.

Dowbor (2008), já identificava como novos caminhos e propostas, o surgimento de nova geração de inovações nos aspectos técnicos de gestão municipal, considerando os avanços da informática e da internet.

Assim, formas alternativas de participação poderão ser decisivas para que cada 
vez mais um maior número de cidadãos possa participar e influenciar na gestão pública.

Com a utilização da Novas Tecnologias de Informação e Comunicação (NTICs), vários processos e procedimentos que eram caríssimos, atualmente, podem ser planejados e executados por custos insignificantes, talvez o maior custo seja o da divulgação. Outros que eram tecnologicamente inviáveis, como por exemplo a manutenção e análises de bancos de dados gigantescos, atualmente, estão sendo utilizados pelas empresas para obterem vantagens competitivas. De certa forma, as grandes administrações públicas acompanham e se beneficiam desses avanços tecnológicos.

Os sistemas de arrecadação de tributos, das grandes cidades, estão totalmente informatizados, desde a cobrança até o recebimento, e tudo pode ser feito sem o contribuinte sair de casa. Outro exemplo, é a eficiente administração de multas captadas por radares fixos e móveis, vinculados ao banco de dados de veículos do Departamento Estadual de Trânsito de São Paulo - DETRAN/SP, que conforme estatística do próprio órgão, a frota total em setembro de 2015 era de 8.105.351 veículos na cidade de São Paulo e de 27.433.541 em todo o Estado. Ainda mais um exemplo, é o Programa Nota Fiscal Paulistana que incentiva o cidadão a exigir nota fiscal sempre que contratar serviços na Cidade de São Paulo, mediante devolução de $30 \%$ do valor do ISS (imposto sobre serviços), e ainda concorre a sorteios mensais de prêmios em dinheiro. Esses exemplos de eficiência, devem ser reproduzidos para alcançar o cidadão e lhe fornecer as melhores condições para participar da gestão pública.
A proposição de um formato alternativo tem a intenção de alcançar diretamente o cidadão, sem nenhum meio de representação intermediária, mediante a utilização de sistemas modernos de informatização, armazenamento e análises de dados.

Pensando na cidade de São Paulo, mas com aplicabilidade em qualquer outro município, a ideia central é criar um grande banco de dados, "big data", de informações sobre as opiniões, sugestões, reclamações e elogios sobre as políticas urbanas em todas as áreas. As informações seriam obtidas mediante questionários disponíveis na internet e para incentivar seu preenchimento o poder público determinaria um percentual ou valor de desconto, no IPTU, ou mediante convênio, na Conta de Luz ou na Conta de Água, de tal forma que terse-ia um questionário respondido por cada domicílio da cidade. Para evitar a exclusão, mecanismos de acesso à internet, que podem ser comunitários, utilizando estruturas já existentes, como por exemplo os CEUs - Centro de Educação Unificado, devem ser pensados.

O propósito não é pura e simplesmente uma pesquisa de satisfação ou criar um sistema com viés de mensuração de popularidade do governo. Também não se trata de um eixo de programa de governo, mas de um programa de planejamento

3 O termo "big data" é utilizado para os bancos de dados com quantidade de informações muito superior ao usual. Atualmente já existem tecnologias para um tratamento analítico de "big data" que possibilitam respostas quase em tempo real. (Informação disponível em: www.ibm.com)

${ }^{4}$ Conforme o Censo 2010 do IBGE, a cidade de São Paulo tinha 3.470 .566 domicílios particulares ocupados. 
de políticas urbanas para a Cidade de São Paulo, consubstanciado na efetiva participação da comunidade local, de forma espontânea e formalmente registrada.

\section{CONSIDERAÇÕES FINAIS E CONCLUSÃO}

Muito embora tenha-se no arcabouço jurídico uma delineação de formas de participação da sociedade na gestão pública, resta claro que, isso não é suficiente. A forma prescritiva de participação serve apenas como referencial de diretrizes básicas para os quase 6.000 municípios brasileiros. $\mathrm{O}$ direito de participação está garantido na Constituição, mas a obrigação não. A obrigação de participar representa o pleno exercício da cidadania, vai além da democracia.

Não adianta acalorar as discussões sobre empoderamento dos cidadãos se, estes, não querem participar do poder. A participação na gestão pública dos municípios é uma questão de conquista, desenvolvimento e preservação do bem-estar comum em nossas cidades e bairros. É a forma democrática de exercer, praticar e fazer valer o poder local em benefício da comunidade.

Cabe ao poder público, despertar, motivar e instigar a sociedade para participar verdadeiramente do planejamento, implementação e execução de políticas públicas. Nesse sentido, temos que as formas tradicionais de participação não são suficientes e eficientes e, muitas formas adotadas constituem-se simples cumprimento de formalidade, para dizer que houve participação popular e calar os críticos. É possível que a partir de novas formas de participação os gestores públicos possam se aproximar cada vez mais da população e entender as necessidades locais para que possam planejar e implementar políticas públicas com a prévia aprovação da sociedade, sem querer, o gestor público, planejar e implementar políticas ou construir obras a partir de uma visão pessoal

\section{REFERÊNCIAS}

BRAGA, J. A experiência do op campinas: questões referentes ao estado e à sociedade civil. Serviço Social \& Saúde, v. 4, n. 4, p. 71-100, 2005.

COSTA, M. B. C. DA. Planejamento urbano participativo : novas institucionalidades e a experiência de Belo Horizonte. Revista Tecer, v. 6, p. 105-121, 2013.

DIAS, M. R. Democracia e novas formas de participação política. Civitas - Revista de Ciências Sociais, v. 4, n. 2, p. 205-209, 2004.

DOWBOR, L. O que é poder local? São Paulo: [s.n.], 2008. Disponível em: $<$ http://dowbor.org/2000/09/ladislau-dowbor-oque-e-poder-local-2008.html/>

Por uma São Paulo Inteligente: Espaços de Governança. Diálogo, n. 23, p. 9-18, 2013.

FERRAZ, L. Novas Formas de Participação Social na Administração Pública : Conselhos Gestores de Políticas Públicas. Revista Eletronica sobre a Reforma do Estado, v. 15, p. 1-10, 2008.

FONSECA, F. Democracia e participação no Brasil: descentralização e cidadania face ao capitalismo contemporâneo. Revista Katálysis, v. 10, n. 2, p. 245-255, 2007.

GARCIA, V. S. Local Management as a Proposal for the Solution of Urban Planning Common Problems in. Revista Electrónica Educare, v. 9, p. 92-103, 2015.

GUERRA, I. Participar porquê e para quê? Reflexões em torno dos efeitos da democracia local na equidade e na legitimidade dos eleitos. 
Revista Crítica de Ciências Sociais, n. 91, p. 121-134, 1 dez. 2010.

MARQUETTI, A. Participação e redistribuição: o orçamento participativo em Porto Alegre. A inovação democrática no Brasil, v. 1, p. 129156, 2003.

RAMÍREZ-ALUJAS, Á. Gobierno abierto es la respuesta : ¿Cuál era la pregunta ? Más Poder Local, n. 12, p. 14-22, 2012.

RIZZI, C. A. A questão da participação da comunidade do Distrito de Perus- ( São Paulo / Brasil ), no projeto MDL Aterro Bandeirantes Apropriação da renda da terra no Distrito de Perus. Revista Franco Brasileira de Geografia, n. $11,2011$.

TOCQUEVILLE, A. DE. O antigo regime e a revolução. São Paulo: Folha de São Paulo, 2015.

WAMPLER, B. A difusão do orçamento participativo brasileiro: "boas práticas" devem ser promovidas? Opinião Pública, v. 14, n. 1, p. 65-95, 2008.

\section{Geraldo Carlos Silvestre}

Doutorando em Administração, Mestre em Ciência

Contábeis e Ciências Atuariais pela Pontifícia Universidade Católica de São Paulo - PUCSP.

\section{Neusa Maria Bastos Fernandes dos Santos}

Professora Doutora e Pesquisadora do Programa de Pós-Graduação da Pontifícia Universidade Católica de São Paulo - PUCSP.

Benedito Geovani Martins de Paiva
Doutorando em Administração, Mestre em Ciência
Contábeis e Ciências Atuariais pela Pontifícia
Universidade Católica de São Paulo - PUCSP.

